\title{
Effect of TRH on $\beta$-gonadotropin subunits in patients with pituitary microincidentalomas
}

\author{
Yona Greenman ${ }^{1}$, Yana Trostanetsky ${ }^{1}$, Dalia Sömjen ${ }^{1}$, Karen Tordjman ${ }^{1}$, Fortune Kohen ${ }^{2}$ and Naftali Stern $^{1}$ \\ ${ }^{1}$ Institute of Endocrinology, Tel Aviv-Elias Sourasky Medical Center, and Sackler Faculty of Medicine, Tel Aviv University, Israel and ${ }^{2}$ Department of \\ Hormone Research, The Weizman Institute of Science, Rehovot, Israel
}

(Correspondence should be addressed to N Stern, Institute of Endocrinology, Tel Aviv-Elias Sourasky Medical Center, 6 Weizman Street, Tel Aviv 64239, Israel)

\begin{abstract}
Objective: To explore the hypothesis that most of the pituitary abnormalities compatible with the diagnosis of microadenoma, and detected in about $10 \%$ of the normal adult population, represent asymptomatic gonadotropinomas.

Design: Patients diagnosed with pituitary microincidentalomas at the Institute of Endocrinology of the Tel Aviv Medical Center were evaluated. Circulating $\beta$-subunits of gonadotropin hormones were measured before and 30, 45, 60 and 90 min after the intravenous injection of $400 \mu \mathrm{g} \mathrm{TRH}$. Patients: Twenty-two patients with pituitary incidentaloma and 16 normal volunteers were tested. Results: In 16 of the 22 patients, an abnormal $\beta$-subunit response was detected after the TRH challenge. Three patients had an abnormal increase in both $\beta$-FSH and $\beta$-LH after TRH administration. Isolated pathological $\beta$-FSH or $\beta$-LH responses were demonstrated in five and eight patients respectively. Six patients had normal basal and stimulated gonadotropin subunit values, raising the possibility that their lesions were not pituitary microadenomas. There was a significant overall difference between the response to TRH of the patient and control groups. In the gonadotropin positive group, comprising 16 patients, serum $\beta$-FSH increased from $6.4 \pm 1.6 \mathrm{ng} / \mathrm{ml}$ to $9.2 \pm 1.3 \mathrm{ng} / \mathrm{ml}$ $(P=0.042) 1 \mathrm{~h}$ after TRH stimulation, whereas no changes were detected in the control group after TRH injection (basal: $4.1 \pm 0.8 \mathrm{ng} / \mathrm{ml}$, peak: $5.1 \pm 0.8 \mathrm{ng} / \mathrm{ml}$; $P=0.15$ ). Serum $\beta$-LH increased from $10.5 \pm 3.2 \mathrm{ng} / \mathrm{ml}$ to $23.4 \pm 4.9 \mathrm{ng} / \mathrm{ml}(P=0.0037)$ at this time, in contrast to a lack of response in controls (basal: $6.4 \pm 1.5 \mathrm{ng} / \mathrm{ml}$, peak: $8.2 \pm 2.3 \mathrm{ng} / \mathrm{ml} ; P=0.24$ ).

Conclusion: In about $73 \%$ of patients with pituitary incidentalomas smaller than $10 \mathrm{~mm}$, TRH elicits an increase in gonadotropin $\beta$-subunits. This observation raises the possibility that non-functioning pituitary micro- and macroadenomas, which share a similar response to TRH, originate in a common ancestor cell type, probably a pituitary gonadotrope.
\end{abstract}

European Journal of Endocrinology 141 17-21

\section{Introduction}

Pituitary incidentalomas have been reported in 5-10\% of unselected computed tomography (CT) or magnetic resonance imaging (MRI) studies of the sella turcica performed in apparently normal individuals (1). In corroboration of these indirect investigations of pituitary anatomy, pituitary microadenomas have been observed in up to $20 \%$ of sequential autopsy analyses of the hypophysis $(2,3)$. Although several prospective studies have indicated that most pituitary microadenomas detected incidentally in imaging studies have an extremely benign course $(4,5)$, it is also quite obvious that pituitary macroadenomas must undergo an apparent 'microadenomatous phase'. This, together with the realization that imaging procedures currently used for clinical purposes cannot uniformly distinguish between microadenomas and non-adenoamatous pituitary lesions, has led to the evolution of follow-up algorithms recommending repeat imaging studies to exclude lesions with significant growth potential (6). Because lesions with biochemical or clinical evidence of hormonal excess account for only a minority of pituitary microincidentalomas, such repeat imaging studies currently provide the only tool for their assessment. It is now widely recognized that nonfunctioning pituitary macroadenomas synthesize and, indeed, secrete glycoprotein-hormone-related peptides such as the $\alpha$ - or $\beta$-subunits of gonadotropins (7). Indeed, as a significant proportion of individuals afflicted with non-functioning tumors have an anomalous increase in circulating concentrations of one or 
more of these peptides in response to thyrotrophinreleasing hormone (TRH), it has been suggested that such responses may comprise an ancillary tool in the diagnostic investigation of non-functioning macroadenomas (8). Imbalanced synthesis and increased secretion of $\beta$-follicle-stimulating hormone $(\beta$-FSH) and $\beta$-luteinizing hormone $(\beta$-LH), rather than intact gonadotropins, appear to be particularly common hallmarks of non-functioning pituitary macroadenomas $(9,10)$.

The purpose of the present study was to explore the hypothesis that pituitary microadenomas likewise secrete $\beta$-subunits of FSH and LH. Because such pituitary lesions are rarely subject to surgical removal, we utilized a TRH challenge in vivo in individuals harboring pituitary microincidentalomas, and measured circulating $\beta$-subunits, following the same protocol as was previously used in non-functioning macroadenomas (11).

\section{Methods}

\section{Participants}

Twenty-two patients ( 17 women and 5 men, mean age$36 \pm 3.5$ years) who were diagnosed as having pituitary lesions compatible with microadenomas on CT and MRI, without clinical or biochemical evidence of hormonal hypersecretion, were included in this study. Headache was the most frequent complaint leading to the imaging studies in this series. These patients underwent thorough neurological evaluation. Other conditions for which the diagnostic investigation resulting in the incidental finding of a pituitary lesion was initiated are listed in Table 1 . One patient presenting with 'galactorrhea' was eventually found to harbor breast cancer that was the cause of breast discharge. During nearly 5 years of follow-up, there have been no evidence of metastatic disease. The patients who presented with sexual dysfunction also underwent formal urological evaluation, including nocturnal penile tumescence testing. In 15 patients, microadenomas between 2 and $8 \mathrm{~mm}$ in size were described. In two additional patients, microadenomas

Table 1 Clinical presentation of patients with imaging findings of pituitary microincidentalomas.

\begin{tabular}{lc}
\hline Clinical symptom & Number of patients \\
\hline Headache & 11 \\
Dizziness & 4 \\
Sexual dysfunction & 4 \\
After road accident & 1 \\
Epilepsy & 1 \\
Galactorrhea & 1 \\
Total & 22 \\
\hline
\end{tabular}

were found in the context of a partially empty sella. In the remaining five patients, diffuse enlargement of the pituitary gland suggesting the presence of a microadenoma, was described (12). In these five patients, common etiologies of pituitary hyperplasia such as pregnancy, target organ failure or hypersecretion of tropic hypothalamic hormones (indicated by pituitary hormone concentrations) were excluded.

None of the patients had clinical symptoms or signs suggestive of growth hormone excess or hypercortisolism. Nevertheless, serum prolactin, insulin-like growth factor (IGF)-I and urinary free cortisol were measured in all patients, to exclude prolactinoma, preclinical acromegaly or Cushing's disease respectively. Specific anterior pituitary hormone deficiencies were defined using standard criteria as described previously (13). Hypogonadism in men was diagnosed when serum concentrations of testosterone or bioavailable testosterone were low (testosterone $<10 \mathrm{nmol} / \mathrm{l}$; bioavailable testosterone $<3.5 \mathrm{nmol} / \mathrm{l}$ ) in the presence of low or normal concentrations of gonadotropins $(<12 \mathrm{IU} / \mathrm{l})$. In premenopausal women, a deficiency in gonadotropin secretion was diagnosed when low or normal concentrations (LH 4-15 IU/l; FSH 1-10 IU/l) were associated with consistently low estradiol concentrations $(<37 \mathrm{pmol} / \mathrm{l}$ after day 21 of the menstrual cycle) or the presence of amenorrhea or oligomenorrhea and infertility. In postmenopausal women, hypogonadism was diagnosed when serum LH or FSH concentrations, or both, were inappropriately low for age $(30 \mathrm{IU} / \mathrm{l})$. Central hypothyroidism was diagnosed when a subnormal serum free thyroxine $\left(\mathrm{fT}_{4}\right)$ concentration $(9 \mathrm{pmol} / \mathrm{l})$ was associated with low or normal concentrations of thyroid-stimulating hormone (TSH; 0.5$5 \mathrm{mU} / \mathrm{l})$. Hypoadrenalism was diagnosed by a subnormal $(<500 \mathrm{nmol} / \mathrm{l})$ cortisol response to a $1 \mu \mathrm{g}$ adrenocorticotropic hormone (ACTH) stimulation test. Twenty of the patients were euthyroid and two received adequate replacement therapy for primary hypothyroidism. All 14 premenopausal women had normal menses. Among the three postmenopausal women, one was receiving hormone replacement therapy, one was receiving tamoxifen for breast cancer, and one had appropriately increased gonadotropin concentrations. Three men had normal gonadal function, whereas two suffered from untreated hypogonadotropic hypogonadism. One patient with empty sella on MRI had partial hypoadrenalism, demonstrated both by the low-dose ACTH test (14) and by insulin-induced hypoglycemia test. All remaining patients had a normal hypothalamicpituitary-adrenal axis. The control group consisted of 16 healthy individuals (11 women and 5 men, mean age $41 \pm 2.3$ years).

\section{Study procedure}

TRH tests were performed both in patients and in controls as previously outlined (11), between 0800 and 
$0900 \mathrm{~h}$. Blood samples for $\beta$-FSH and $\beta$-LH were collected immediately before and 30, 45, 60 and $90 \mathrm{~min}$ after the i.v. injection of $400 \mu \mathrm{g}$ TRH. An increase in circulating $\beta$-subunits was considered significant when concentrations increased by $50 \%$ or more over basal values (11). The study procedure was approved by the Institutional Helsinki Committee and patients and volunteers gave informed consent to participate in it.

\section{Hormone measurements}

All hormones were measured in duplicate using commercial assay kits as follows: tri-iodothyronine, cortisol, 17 $\beta$-estradiol, testosterone, RIA (Diagnostic Products Corp., Los Angeles, CA, USA); TSH, immunoradiometric assay, magnetic solid phase (Serono Diagnostics, Woking, United Kingdom); $\mathrm{fT}_{4}, \mathrm{LH}$ and FSH, RIA (Amerlex, Amersham, Aylesbury, Bucks, United Kingdom); prolactin, enzyme immunoassay (Boehringer Mannheim, Mannheim, Germany, normal range $5-20 \mu \mathrm{g} / \mathrm{l})$. Bioavailable testosterone was measured by a modification of a method described by Tremblay \& Duke (15), as described previously (13).

\section{Measurement of $\beta$-subunits}

$\beta$-FSH and $\beta$-LH were measured by fluoroimmunoassays developed in our laboratory, as described previously (11). Briefly, for $\beta$-FSH, microtiter strips were coated with a monoclonal antibody raised to human $\beta$-FSH. Serum samples were applied to the strips and incubated at room temperature for $6 \mathrm{~h}$ with constant shaking. After washing, the strips were incubated overnight $\left(4^{\circ} \mathrm{C}\right)$ with antihuman $\beta$-FSH polyclonal antibody obtained from the national pituitary hormone distribution program at the National Institutes of Health (NIH) (Bethesda, MD, USA). Europium-labeled antirabbit IgG antibodies were subsequently added and, after $4 \mathrm{~h}$ incubation at room temperature, washings and soaking in an enhancement solution, the wells were counted in a time-resolved fluorimeter (LKB, Stockholm, Sweden). $\beta$-LH was also determined by a fluoroimmunoassay developed in our laboratory (11). In brief, microtiter strips were coated with a buffer containing affinity-pure goat antirabbit antibody (Jackson Immunoresearch Laboratories, Inc., West Grove, PA, USA). Samples were applied to the strips and incubated with europium-labeled $\beta$-LH and antihuman $\beta$-LH antibodies obtained from the NIH for $3 \mathrm{~h}$ at room temperature. After washes and incubation in an enhancement solution, the strips were counted in the time-resolved fluorimeter.

In both assays, crossreactivity with LH, FSH, human chorionic gonadotrophin (hCG), $\beta$-hCG, $\beta$-LH or $\beta$-FSH, $\alpha$-subunits and TSH was less than $0.1 \%$. Assay sensitivity was $0.1 \mathrm{ng} / \mathrm{ml}$. The intra-assay coefficient of variation was $7 \%$ for $\beta$-FSH and $8 \%$ for $\beta$-LH, and the interassay coefficient of variation was $8 \%$ for $\beta$-FSH and
$10 \%$ for $\beta$-LH. The normal ranges for both subunits were determined in 32 healthy individuals (age range 30-87 years, nine of whom were postmenopausal women), with no known endocrinopathy. The upper limit for $\beta$-FSH was $9.3 \mathrm{ng} / \mathrm{ml}$ for postmenopausal women and $6.5 \mathrm{ng} / \mathrm{ml}$ for the remainder of the population. The upper limit for $\beta$-LH was $13.3 \mathrm{ng} /$ $\mathrm{ml}$ (for men and pre- and postmenopausal women alike).

\section{Statistical analysis}

Results are expressed as means \pm s.E.M. Data were analyzed by multivariate analysis of variance with repeated measures and the paired Student's $t$-test for specific comparisons. A two tailed $P$ value of less than 0.05 was considered of statistical significance.

\section{Results}

$\beta$-FSH increased from $5.7 \pm 1.3 \mathrm{ng} / \mathrm{ml}$ to $8.1 \pm 1.2 \mathrm{ng} / \mathrm{ml}$ at $60 \mathrm{~min}(P=0.012)$ in patients, whereas no significant changes in $\beta$-FSH were seen in the control group after $\mathrm{TRH}$ injection (basal: $4.1 \pm 0.8 \mathrm{ng} / \mathrm{ml}$, peak: $5.1 \pm$ $0.8 \mathrm{ng} / \mathrm{ml} ; P=0.15)$. FSH concentrations remained unchanged after TRH challenge, in both the patient and the control populations.

$\beta$-LH increased from $9.1 \pm 2.4 \mathrm{ng} / \mathrm{ml}$ to $20 \pm 4 \mathrm{ng} / \mathrm{ml}$ at $60 \mathrm{~min}(P=0.002)$ in patients, and did not significantly change in the control subjects after TRH stimulation (basal: $6.4 \pm 1.5 \mathrm{ng} / \mathrm{ml}$, peak: $8.2 \pm 2.3 \mathrm{ng} /$ $\mathrm{ml} ; P=0.24$ ). There was a significant overall difference between patient and control groups regarding the $\beta$-LH response to TRH stimulation $(P=0.047)$. LH concentrations remained unchanged after TRH injection in both groups.

Because pituitary lesions incidentally found in imaging procedures do not necessarily represent microadenomas (3), we classified the patients according to their response to TRH, using the criteria described in the Methods section. Three patients had abnormal increases in both $\beta$-FSH and $\beta$-LH after TRH administration. Isolated pathological $\beta$-FSH or $\beta$-LH responses were demonstrated in five and eight patients respectively. Six patients had normal basal and stimulated gonadotropin subunit levels, raising the possibility that their lesions were not pituitary microadenomas. When these six patients were excluded from the analysis, the difference in $\beta$-subunits between patients and controls was further accentuated. In the 16 patients thus presumed to have pituitary microadenomas, serum $\beta$-FSH increased from $6.4 \pm 1.6 \mathrm{ng} / \mathrm{ml}$ to $9.2 \pm 1.3 \mathrm{ng} / \mathrm{ml}(P=0.042) 1$ hour after TRH stimulation $(P=0.003$ compared with peak control values), whereas serum $\beta$-LH increased from $10.5 \pm 3.2 \mathrm{ng} / \mathrm{ml}$ to $23.4 \pm 4.9 \mathrm{ng} / \mathrm{ml}(P=0.0037)$ at this time $(P=0.004$ compared with peak control values) (Fig. 1). There was a significant overall difference between patient and control groups regarding the 
$\beta$-LH response to TRH stimulation $(P=0.01)$. Individual patient responses to TRH stimulation are depicted in Fig. 2.

\section{Discussion}

Our results provide indirect evidence that a significant proportion of pituitary microadenomas secrete $\beta$-subunits of gonadotropin hormones. In most patients with pituitary microadenomas, this is not evident in basal conditions, in which circulating $\beta$-FSH and $\beta$-LH concentrations are within the control range. However, upon challenge with TRH, individuals harboring pituitary incidentalomas, apparently of an adenomatous origin, respond with an abnormal secretory surge
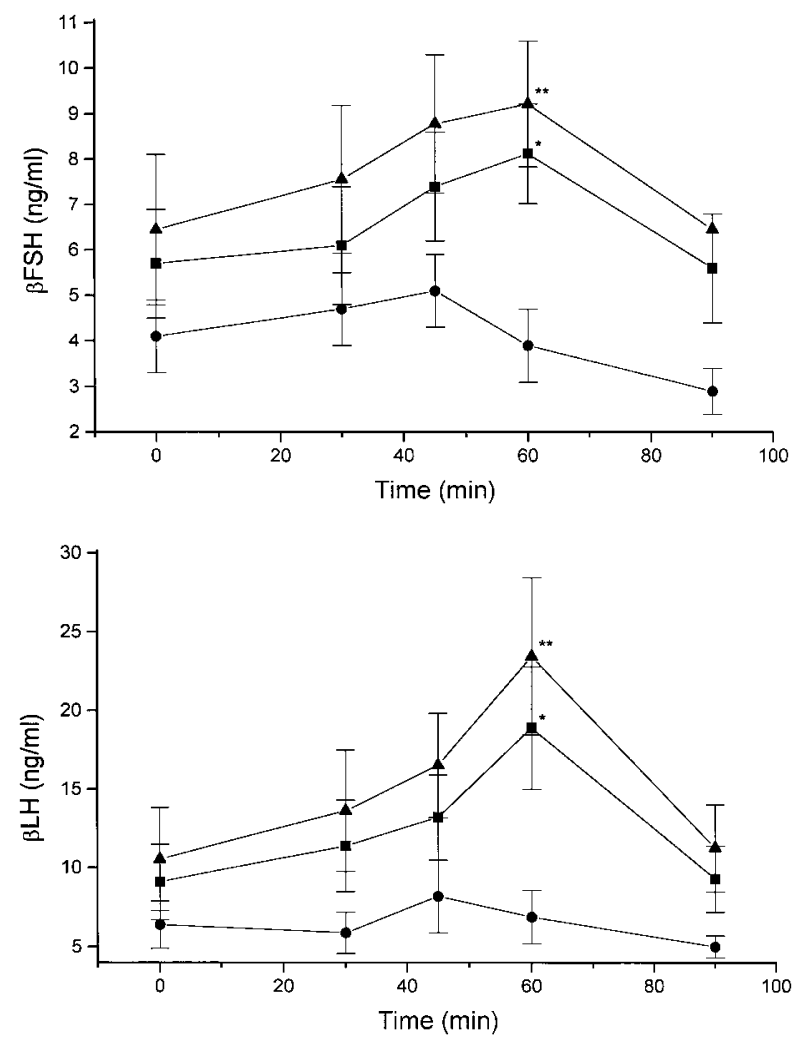

Figure 1 TRH-stimulated $\beta$-FSH (upper panel) and $\beta$-LH (lower panel) concentrations in the entire patient population $(\boldsymbol{\square})$, in the 16 patients with the presumed diagnosis of pituitary microadenoma $(\boldsymbol{\Delta})$ and in controls $(\bullet)$. Upper panel: $P=0.012$ for the overall increase in serum $\beta$-FSH in all patients (ANOVA), $P=0.042$ for the overall increase in serum $\beta$-FSH in the presumed microadenoma group (ANOVA), $P=$ non-significant (NS) for the pre- compared with post$\mathrm{TRH} \beta$-FSH concentrations in the control group. ${ }^{*} P=0.02$,

${ }^{* *} P=0.003$ compared with control group. Lower panel: $P=0.002$ for the overall increase in $\beta$-LH in all patients (ANOVA), $P=0.0037 \mathrm{for}$ the overall increase in serum $\beta$-LH in the presumed microadenoma subgroup (ANOVA), $P=\mathrm{NS}$ for pre- compared with post-TRH $\beta$ - $\mathrm{LH}$ concentrations in the control group. ${ }^{*} P=0.015,{ }^{* *} P=0.004$ compared with control group. $P=0.01$ for the overall difference between the presumed microadenoma and control groups regarding the $\beta$-LH response to $\mathrm{TRH}$ stimulation.

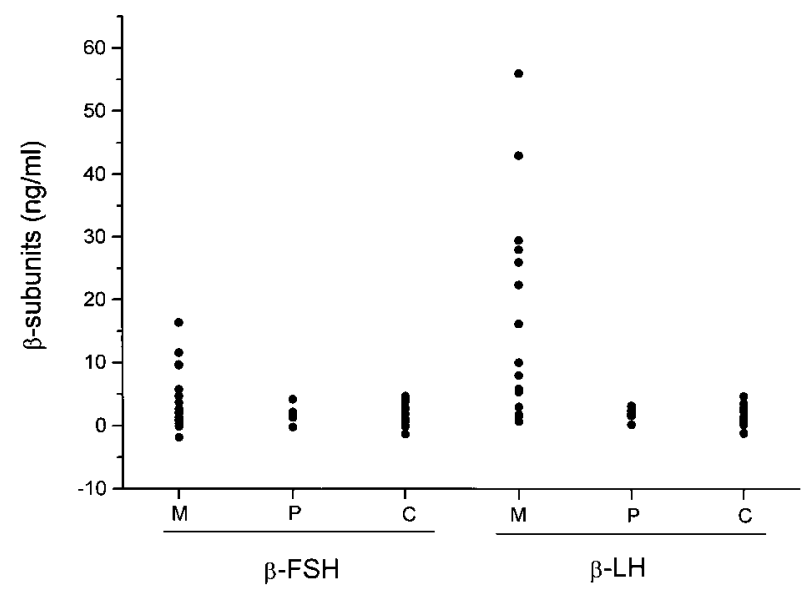

Figure 2 Individual patients' $\beta$-subunits response to TRH stimulation. Values are post-TRH peak minus basal concentrations. $M$, patients presumed to harbor microadenomas; $P$, patients whose microincidentalomas are of presumed non-adenomatous nature; C, controls.

of $\beta$-FSH, $\beta$-LH, or both peptides. This response is distinct from the rather constant post-TRH concentrations in normal individuals, and is clearly reminiscent of the gonadotropin $\beta$-subunit response to TRH in patients with pituitary macroadenomas $(11,16)$.

Whereas compelling evidence exists that pituitary macroadenomas express the $\beta$-FSH and the $\beta$-LH genes and, indeed, increase the release of these peptides when exposed to TRH in vitro $(11,17,18)$, this is the first report to suggest that adenomatous cells comprising pituitary microincidentalomas possess a similar biosynthetic capacity. Definitive proof will obviously depend on the identification of these peptides in vitro by immunohistochemistry, the detection of $\beta$-FSH $/ \beta$-LH mRNA, or the release of gonadotropin $\beta$-subunits in in vitro studies, as previously reported in pituitary macroadenomas. Notwithstanding the need for such evidence in pituitary microadenomas, it will undoubtedly be much more difficult to obtain, because of obvious quantitative limitations: non-functioning pituitary microadenomas are very rarely extracted surgically and, even in the rare event of such removal, scant and poorly proliferating cellular harvest is likely. Postmortem specimens may provide an alternative source, but they fall short of providing the opportunity for appropriate correlation with the in vivo situation.

The TRH-induced increase in gonadotropin $\beta$-subunits in patients with pituitary incidentalomas is intriguing in several respects. First, it strongly resembles the in vivo response to TRH in individuals with pituitary macroadenomas, thus suggesting that adenomatous cells of both non-functioning micro- and macroadenomas may be derived from pituitary gonadotropes. Secondly, the $\beta$-FSH/ $\beta$-LH responses to TRH in pituitary microadenomas were quantitatively similar to those observed in macroadenomas. For example, the peak post-TRH $\beta$-LH that 
we have reported here is $23.4 \pm 4.9 \mathrm{ng} / \mathrm{ml}$, compared with values of $25.8 \pm 2.9 \mathrm{ng} / \mathrm{ml}$ previously observed by us in pituitary macroadenomas (11). Similarly, the peak $\beta$-FSH concentrations are $9.2 \pm 1.3 \mathrm{ng} / \mathrm{ml}$ in our patients with microadenomas, compared with $8.4 \pm$ $1 \mathrm{ng} / \mathrm{ml}$ in a series of patients with macroadenomas (11). Given the large differences in tumor volume between micro- and macroadenomas, and assuming a common ancestor cell, these rather small quantitative differences in peptide responses suggest that large tumors may be less efficient at $\beta$-FSH $/ \beta$-LH biosynthesis, perhaps reflecting some further cell dedifferentiation. Thirdly, about $30 \%$ of the patients with pituitary incidentalomas included in this series neither had increased basal $\beta$-FSH $/ \beta$-LH concentrations, nor did they show an abnormal increase in the concentrations of these peptides after TRH administration. These lesions may be the source of yet unidentified hormonerelated secretory products, but they are more likely to represent pituitary incidentalomas of non-adenomatous nature. If this is the case, the findings in the present study may form the basis for a potential distinction between 'true' microadenomas and other pituitary incidentalomas such as imaging artifacts, gliomas, micrometastases, infarcts, etc., judged by $\beta$-subunits responses. Until the nature of the microadenomatous cells is directly determined, however, the linkage between an anomalous increase in gonadotropin $\beta$-subunits and the presence of a pituitary microadenoma remains somewhat conjectural. Further, the extent to which a positive $\beta$-FSH $/ \beta$-LH response to TRH will affect the diagnostic investigation and follow-up of pituitary incidentaloma must be examined in prospective studies.

In summary, in about $73 \%$ of patients with pituitary incidentalomas smaller than $10 \mathrm{~mm}$, TRH elicits an increase in gonadotropin $\beta$-subunits. This observation raises the possibility that non-functioning pituitary micro- and macroadenomas, which share a similar response to $\mathrm{TRH}$, originate in a common ancestor cell type, probably a pituitary gonadotrope.

\section{References}

1 Hall WA, Luciano MG, Doppman JL, Patronas NJ \& Oldfield EH. Pituitary magnetic resonance imaging in normal human volunteers: occult adenomas in the general population. Annals of Internal Medicine 1994120 817-820.

2 Parent AD, Bebin J \& Smith RR. Incidental pituitary adenomas. Journal of Neurosurgery 198154 228-231.
3 Teramoto A, Hirakawa K, Sanno N \& Osamura Y. Incidental pituitary lesions in 1000 unselected autopsy specimens. Radiology $1994193161-164$.

4 Donovan LE \& Corenblum B. The natural history of the pituitary incidentaloma. Archives of Internal Medicine 1995155 181-183.

5 Reincke M, Allolio B, Saeger W, Menzel J \& Winkelmann W. The 'incidentaloma' of the pituitary gland. Is neurosurgery required? Journal of the American Medical Association $19902632772-$ 2776.

6 Molitch ME. Pituitary incidentalomas. Endocrinology and Metabolism Clinics of North America 199726 725-740.

7 Greenman Y \& Melmed S. Diagnosis and management of nonfunctioning pituitary tumors. Annual Review of Medicine 199647 95-106.

8 Daneshdoost L, Gennarelli TA, Bashey HM, Savino PJ, Sergott RC, Bosley TM \& Snyder PJ 1991 Recognition of gonadotroph adenomas in women. New England Journal of Medicine 324 589-594.

9 Snyder PJ, Bashey HM, Kim SU \& Chappel SC. 1984 Secretion of uncombined subunits of luteinizing hormone by gonadotroph cell adenomas. Journal of Clinical Endocrinology and Metabolism 59 1169-1175.

10 Katzenelson L. Alexander JM, Bikkal HA, Jameson L, Hsu DW \& Klibanski A. Imbalanced follicle-stimulating hormone $\beta$-subunit hormone byosynthesis in human pituitary adenomas. Journal of Clinical Endocrinology and Metabolism 199274 1343-1351.

11 Somjen D, Tordjman K, Kohen F, Baz M, Razon N, Ouaknine G \& Stern N. Combined $\beta \mathrm{FSH}$ and $\beta \mathrm{LH}$ response to TRH in patients with clinically non-functioning pituitary adenomas. Clinical Endocrinology 199746 555-562.

12 Pressman BD. Pituitary imaging. In The Pituitary, pp 663-686. Ed S Melmed. Cambridge, MA, USA: Blackwell Science Inc., 1995.

13 Greenman Y, Tordjman K, Kisch E, Razon N, Ouaknine G \& Stern N. Relative sparing of anterior pituitary function in patients with growth hormone-secreting macroadenomas: comparison with nonfunctioning macroadenomas. Journal of Clinical Endocrinology and Metabolism 199580 1577-1583.

14 Tordjman K, Jaffe A, Grazas N, Apter C \& Stern N. The role of the low dose (1 microgram) adrenocorticotropin test in the evaluation of patients with pituitary diseases. Journal of Clinical Endocrinology and Metabolism 199580 1301-1305.

15 Tremblay RR \& Dube JY. Plasma concentration of free non TeBG bound testosterone in women on oral contraception. Contraception $197410599-605$.

16 Gil-del-Alamo P, Pettersson KSI, Saccomanno K, Spada A, Faglia G \& Beck-Peccoz P. Abnormal response of luteinizing hormone beta subunit to thyrotropin-releasing hormone in patients with nonfunctioning pituitary adenoma. Clinical Endocrinology 199441 661-666.

17 Saccomano K, Bassetti M, Lania A, Losa M, Faglia G \& Spada A. Immunodetection of glycoprotein hormone subunits in nonfunctioning and glycoprotein hormone-secreting pituitary adenomas. Journal of Endocrinological Investigation 199720 59-64.

18 Snyder PJ, Bashey H, Phillips JL \& Gennarelli TA. Comparison of hormonal secretory behavior of gonadotroph cell adenomas in vivo and in culture. Journal of Clinical Endocrinology and Metabolism $1985611061-1065$.

Received 27 January 1999

Accepted 25 March 1999 